\title{
Synergetic Hybrid Aerogels of Vanadia and Graphene as Electrode Materials of Supercapacitors
}

\author{
Xuewei Fu ${ }^{1}$, Yuming Chen ${ }^{2}$, Yu Zhu ${ }^{2}$ and Sadhan C. Jana ${ }^{1, *}$ \\ 1 Department of Polymer Engineering, The University of Akron, Akron, OH 44325, USA; xf8@zips.uakron.edu \\ 2 Department of Polymer Science, The University of Akron, Akron, OH 44325, USA; \\ yc67@zips.uakron.edu (Y.C.); yzhu@uakron.edu (Y.Z.) \\ * Correspondence: janas@uakron.edu; Tel.: +330-972-8293; Fax: +330-972-3406 \\ Academic Editor: Dusan Losic
}

Received: 7 April 2016; Accepted: 11 July 2016; Published: 4 August 2016

\begin{abstract}
The performance of synergetic hybrid aerogel materials of vanadia and graphene as electrode materials in supercapacitors was evaluated. The hybrid materials were synthesized by two methods. In Method I, premade graphene oxide (GO) hydrogel was first chemically reduced by $\mathrm{L}$-ascorbic acid and then soaked in vanadium triisopropoxide solution to obtain $\mathrm{V}_{2} \mathrm{O}_{5}$ gel in the pores of the reduced graphene oxide (rGO) hydrogel. The gel was supercritically dried to obtain the hybrid aerogel. In Method II, vanadium triisopropoxide was hydrolyzed from a solution in water with GO particles uniformly dispersed to obtain the hybrid gel. The hybrid aerogel was obtained by supercritical drying of the gel followed by thermal reduction of GO. The electrode materials were prepared by mixing $80 \mathrm{wt} \%$ hybrid aerogel with $10 \mathrm{wt} \%$ carbon black and $10 \mathrm{wt} \%$ polyvinylidene fluoride. The hybrid materials in Method II showed higher capacitance due to better interactions between vanadia and graphene oxide particles and more uniform vanadia particle distribution.
\end{abstract}

Keywords: supercapacitors; aerogel; hybrid materials; graphene; vanadia

\section{Introduction}

Supercapacitors have gained considerable attention as energy storage devices due to their high storage capability, excellent discharge-charge rates, long life cycle, and low maintenance costs [1]. Supercapacitors are divided into two categories based on the mechanism of energy storage-(1) electrochemical double-layer capacitors (EDLCs) based on carbon materials, and (2) pseudocapacitors based on electrode materials composed of redox metal oxides or conducting polymers [2]. The capacitance of EDLCs originates from the electrical double-layer formed at the electrode-electrolyte interface. The charge accumulation, in this case, occurs via a non-Faradaic process [2,3]. In the case of pseudocapacitors, the capacitance is derived from a Faradaic process whereby the redox reactions of the electrode materials and the electrolyte occur at the electrode surfaces [4,5].

Graphene aerogels consisting of three-dimensional networks of graphene sheets were considered as electrode materials of supercapacitors in recent investigations [6]. The hierarchically-porous structures with high surface area attributed to aerogels and the high values of electrical conductivity of graphene sheets were found responsible for high specific capacitance of $128 \mathrm{~F} / \mathrm{g}$ at a current density of $50 \mathrm{~mA} \cdot \mathrm{g}^{-1}$ [7]. However, higher capacitance than most other EDLCs cannot be achieved due to the limitations imposed by the surface area [2]. Some transition metal oxides with various valences were extensively studied for pseudocapacitance produced via redox reactions of the electrode materials and the electrolyte [2]. Among the transition metal oxides, $\mathrm{V}_{2} \mathrm{O}_{5}$ is considered a promising electrode material due to its large specific capacitance and easy synthesis process [8]. Although $\mathrm{V}_{2} \mathrm{O}_{5}$ exhibits satisfactory specific capacitance of 214-346 F/g in $\mathrm{KCl}$ [3], its applications and development are 
somewhat restricted due to poor cycle stability caused by the collapse of the structures during the charge-discharge process and the low values of electrical conductivity [8-10]. These obstacles must be removed to capitalize on the higher specific capacitance values of $\mathrm{V}_{2} \mathrm{O}_{5}$, possibly through identification of a set of synergistic materials.

In this work, such a synergy was obtained by combining $\mathrm{V}_{2} \mathrm{O}_{5}$ and graphene aerogels into single hybrid materials. In these materials, graphene contributes a smooth path for charge transport and provides mechanically stronger structures, while the organized $\mathrm{V}_{2} \mathrm{O}_{5}$ particles provide a scope for energy storage. This paper presents two facile and green methods for preparation of hybrid aerogels based on $\mathrm{V}_{2} \mathrm{O}_{5}$ and reduced graphene oxide (rGO). In addition, the synergetic materials in this work avoid the often-encountered compatibility issues of two entirely different materials in the hybrids [11].

\section{Experimental}

\subsection{Materials}

Natural graphite powder (99.9995\% purity, UCP-1 grade) used in the synthesis of graphene was purchased from Alfa Aesar (Ward Hill, MA, USA). Potassium peroxodisulfate ( $\geqslant 99.0 \%$ ), phosphorus pentoxide $(\geqslant 98.0 \%)$, potassium permanganate $(\geqslant 99.9 \%$ purity), and acetone $(\geqslant 99.5 \%)$ were purchased from Sigma Aldrich (Milwaukee, WI, USA). Hydrogen peroxide (30 wt \% solution) was purchased from EMD (Billerica, MA, USA). The precursor material vanadium triisopropoxide ( $>98.7 \%$ purity) and L-ascorbic acid ( $\geqslant 99.0 \%$ purity) were purchased from VWR Inc. (Radnor, PA, USA). All aqueous solutions and dispersions were produced using deionized (DI) water.

\subsection{Preparation of Graphene Oxide Dispersions}

Graphite powder was oxidized to graphene oxide (GO) via a modified Hummers method reported elsewhere [6]. Briefly, $12 \mathrm{~mL}$ concentrated $\mathrm{H}_{2} \mathrm{SO}_{4}$ was heated up to $90^{\circ} \mathrm{C}$ in a $100 \mathrm{~mL}$ beaker. Then $2.5 \mathrm{~g}$ $\mathrm{K}_{2} \mathrm{~S}_{2} \mathrm{O}_{8}$ and $2.5 \mathrm{~g} \mathrm{P}_{2} \mathrm{O}_{5}$ were added into the beaker with gentle stirring until the materials dissolved completely. The solution was cooled down to $80^{\circ} \mathrm{C}$ and $3 \mathrm{~g}$ graphite powder was added into it. The mixture was kept at $80^{\circ} \mathrm{C}$ for $5 \mathrm{~h}$ and then cooled down to room temperature, diluted with $500 \mathrm{~mL}$ DI water, and allowed to stand overnight. The solid was filtered, washed with DI water to remove the residual acid, and allowed to dry under ambient conditions. The solid was transferred into $120 \mathrm{~mL}$ cold concentrated $\mathrm{H}_{2} \mathrm{SO}_{4}$ at $0{ }^{\circ} \mathrm{C}$ and $15 \mathrm{~g} \mathrm{KMnO}_{4}$ was added to it slowly under stirring. The mixture was kept at $35^{\circ} \mathrm{C}$ under stirring for $2 \mathrm{~h}$ to obtain graphene oxide (GO), after which it was diluted slowly with $250 \mathrm{~mL}$ DI water to keep the temperature below $50^{\circ} \mathrm{C}$. The mixture was stirred for $2 \mathrm{~h}$, diluted with $700 \mathrm{~mL}$ DI water, and mixed with $20 \mathrm{~mL} 30 \mathrm{wt} \% \mathrm{H}_{2} \mathrm{O}_{2}$ solution. The mixture containing GO particles was allowed to stand for $12 \mathrm{~h}$ and the solid was washed with $1 \mathrm{~L} 5 \mathrm{wt} \% \mathrm{HCl}$ solution to remove the metal ions, followed by $1 \mathrm{~L}$ DI water to remove the residual acid. GO was dispersed in DI water by ultrasonication for $40 \mathrm{~m}$ after which the concentration of $\mathrm{GO}$ in the dispersion was adjusted to $7 \mathrm{mg} / \mathrm{mL}$.

\subsection{Method I: Preparation of Graphene-Templated Hybrid Aerogel}

The hybrid aerogel was prepared in this method using a general procedure reported elsewhere [12]. GO dispersion was diluted to $2 \mathrm{mg} / \mathrm{mL}$ and dispersed using ultrasonication for $40 \mathrm{~min}$. L-ascorbic acid $(0.42 \mathrm{~g})$ was added into $70 \mathrm{~mL}$ GO dispersion under stirring until it completely dissolved. The mixture was heated to $50{ }^{\circ} \mathrm{C}$ and allowed to stand for $12 \mathrm{~h}$ to form reduced graphene oxide (rGO) gel. The rGO gel was washed with large quantities of DI water over three days to remove the soluble ions and the residual L-ascorbic acid, followed by solvent exchange with acetone for three days to remove water. The graphene gel in acetone was soaked overnight in a solution of $0.8 \mathrm{~mL} \mathrm{VO}\left(\mathrm{OC}_{3} \mathrm{H}_{7}\right)_{3}$ in $4.5 \mathrm{~mL}$ acetone. This allowed diffusion of $\mathrm{VO}\left(\mathrm{OC}_{3} \mathrm{H}_{7}\right)_{3}$ molecules into the pores of the graphene gel. The gel was then transferred into another vial filled with $3 \mathrm{~mL}$ acetone and $1 \mathrm{~mL}$ DI water to induce hydrolysis of $\mathrm{VO}\left(\mathrm{OC}_{3} \mathrm{H}_{7}\right)_{3}$ and condensation of vanadium hydroxide into $\mathrm{V}_{2} \mathrm{O}_{5}$ gel inside the pores of the graphene gel. The molar ratio $\mathrm{VO}\left(\mathrm{OC}_{3} \mathrm{H}_{7}\right)_{3}$ : water:acetone was kept at 1:60:45. The number of moles $(n)$ of $\mathrm{VO}\left(\mathrm{OC}_{3} \mathrm{H}_{7}\right)_{3}$ was estimated from the relationship 
$n=\mathrm{CVO}\left(\mathrm{OC}_{3} \mathrm{H}_{7}\right)_{3} \cdot V_{\text {graphene gel }}$, where $\mathrm{C}_{\mathrm{VO}(\mathrm{OC} 3 \mathrm{H} 7)_{3}}$ is the molar concentration of $\mathrm{VO}\left(\mathrm{OC}_{3} \mathrm{H}_{7}\right)_{3}$ and $V_{\text {graphene gel }}\left(=\pi \cdot r^{2} \cdot l\right)$ is the volume of the cylinder of graphene gel, with $r$ and $l$ as the radius and the length of the graphene specimen, respectively.

The hybrid gel was allowed to stand for three days at room temperature for aging, after which the gel was washed with acetone for two days to remove the residual water. The hybrid gel was dried using supercritical $\mathrm{CO}_{2}$. Three groups of hybrid aerogels were prepared at different concentrations of $\mathrm{VO}\left(\mathrm{OC}_{3} \mathrm{H}_{7}\right)_{3}$ with the molar ratio of $\mathrm{VO}\left(\mathrm{OC}_{3} \mathrm{H}_{7}\right)_{3}: \mathrm{H}_{2} \mathrm{O}$ :acetone kept constant. The concentration of $\mathrm{VO}\left(\mathrm{OC}_{3} \mathrm{H}_{7}\right)_{3}$ was maintained at $0.64 \mathrm{M}, 0.82 \mathrm{M}$ and $1 \mathrm{M}$, and the corresponding hybrid aerogels are denoted in the rest of the paper as $\mathrm{rGO}-\mathrm{V}_{2} \mathrm{O}_{5}-0.64$, $\mathrm{rGO}-\mathrm{V}_{2} \mathrm{O}_{5}-0.82$, and $\mathrm{rGO}-\mathrm{V}_{2} \mathrm{O}_{5}-1$, respectively.

\subsection{Method II: Preparation of Hybrid Aerogel Via One-Pot Synthesis}

The hydrolysis of $\mathrm{VO}\left(\mathrm{OC}_{3} \mathrm{H}_{7}\right)_{3}$ yields vanadium hydroxide. The polar functional groups, such as $-\mathrm{COOH}$ and $-\mathrm{OH}$, on graphene surfaces can interact with vanadium hydroxide or its oligomers. The vanadium hydroxide forms an octahedral complex by one $\mathrm{H}_{2} \mathrm{O}$ molecule opposite to the $\mathrm{V}=\mathrm{O}$ bond, and the hydroxyl group on the graphene oxide surfaces coordinating at the equatorial plane as shown in Figure S1 [13]. These coordination bonds facilitate the growth of VO oligomers and enhance their interactions with the graphene sheets.

A typical preparation process is as follows. $1 \mathrm{~mL} \mathrm{VO}\left(\mathrm{OC}_{3} \mathrm{H}_{7}\right)_{3}$ and $5 \mathrm{~mL}$ acetone were mixed in a vial in an ice bath under vigorous stirring. As gelation of $\mathrm{VO}\left(\mathrm{OC}_{3} \mathrm{H}_{7}\right)_{3}$ occurs rapidly, all of the chemicals were kept in an ice bath for 15 min prior to mixing. A $4 \mathrm{~mL} \mathrm{GO}$ dispersion was added into the vial and mixed to induce hydrolysis of $\mathrm{VO}\left(\mathrm{OC}_{3} \mathrm{H}_{7}\right)_{3}$. The concentration of $\mathrm{GO}$ in aqueous dispersions was maintained at $2 \mathrm{mg} / \mathrm{mL}, 4 \mathrm{mg} / \mathrm{mL}$, and $6 \mathrm{mg} / \mathrm{mL}$. The corresponding materials are designated as $\mathrm{V}_{2} \mathrm{O}_{5}-\mathrm{rGO}-2, \mathrm{~V}_{2} \mathrm{O}_{5}-\mathrm{rGO}-4$, and $\mathrm{V}_{2} \mathrm{O}_{5}-\mathrm{rGO}-6$, respectively, in the rest of the paper.

The resultant liquid was transferred into a cylindrical mold and the gel formed in approximately $1 \mathrm{~min}$. The gel was aged for two days at room temperature in the sealed cylindrical mold. During the aging process, the color of the gel changed from dark red to deep green indicating the presence of $\mathrm{V}^{4+}$ ions [14]. The final gel was washed with acetone five times in $5 \mathrm{~h}$ intervals to remove the residual water from the gel. The hybrid aerogel was obtained by supercritical drying of the gel using $\mathrm{CO}_{2}$. The as-prepared aerogel was heated in air at $300{ }^{\circ} \mathrm{C}$ for $90 \mathrm{~min}$ to reduce GO into graphene [15]. Simultaneously, $\mathrm{V}^{4+}$ ions underwent oxidation to $\mathrm{V}^{5+}$ ions. In addition, $\mathrm{V}_{2} \mathrm{O}_{5}$ underwent partial crystallization due to the thermal treatment.

\subsection{Characterization}

The morphology of the prepared materials was examined by scanning electron microscopy (SEM; JEOL-7401, Boston, MA, USA) and transmission electron microscopy (TEM; JEOL-1230, Boston, MA, USA). X-ray diffraction (Bruker AXS Dimension D8, Billerica, MA, USA) was carried out to study the crystalline structures of the samples. The chemical structures were analyzed by Raman spectroscopy (Horiba LabRam HR, Kyoto, Japan) and Fourier transform infrared spectroscopy (Nicolet 380, Cleveland, OH, USA). The surface properties were characterized by Micromeritics Tristar II 3020 Analyzer (Micromeritics, Norcross, GA, USA), which include Brunauer-Emmett-Teller (BET) surface area and Barrett-Joyner-Halenda (BJH) pore size distribution. The thermal stability of the prepared samples was determined from thermogravimetric analysis (TGA) (TA Instrument, New Castle, DE, USA) in air with a $10^{\circ} \mathrm{C} / \mathrm{min}$ heating rate and air flow rate of $60 \mathrm{~mL} / \mathrm{min}$.

\subsection{Electrochemical Measurements}

The electrochemical performance of the materials was determined using a symmetrical two-electrode system with $1 \mathrm{M} \mathrm{Na}_{2} \mathrm{SO}_{4}$ aqueous solution as the electrolyte. The electrode was prepared by mixing $80 \mathrm{wt} \%$ hybrid aerogel materials as the active materials, $10 \mathrm{wt} \%$ PVDF as the binder, and $10 \mathrm{wt} \%$ carbon black as the conducting material into a slurry. The slurry was dropped onto a nickel foam spreading to $1 \mathrm{~cm}^{2}$ area and the materials were dried at $110{ }^{\circ} \mathrm{C}$ for $12 \mathrm{~h}$ in vacuum to remove the solvent. The coated nickel foam was then compressed under $10 \mathrm{MPa}$ pressure. The weight of each active material was kept in the range of $0.45-0.5 \mathrm{mg}$. Cyclic voltammetry $(\mathrm{CV})$ tests with 
potential window of -1 to $1 \mathrm{~V}$ at scanning rates varying from 10 to $100 \mathrm{mV} / \mathrm{s}$ and electrochemical impedance spectroscopy (EIS) with frequency range of $0.01 \mathrm{~Hz}$ to $100 \mathrm{kHz}$ were performed on the CHI600E electrochemical workstation (CH Instruments, Inc., Austin, TX, USA). The galvanostatic charge/discharge tests were carried out between -1 to $1 \mathrm{~V}$. The specific capacitance $(\mathrm{C})$ for a single electrode according to the charge/discharge curve was obtained from the following relationship:

$$
\mathrm{C}=2 I \Delta t /(m \Delta V)
$$

where $I$ is the applied constant current, $m$ is the mass of the active materials in one electrode, $\Delta t$ is the discharging time, and $\Delta V$ is the potential window.

\section{Results and Discussions}

\subsection{Hybrid Aerogels Produced in Method I}

For hybrid aerogels produced in Method I, the concentration of $\mathrm{VO}\left(\mathrm{OC}_{3} \mathrm{H}_{7}\right)_{3}$ in solution was varied from $0.64 \mathrm{M}$ to $1 \mathrm{M}$. The SEM image of rGO aerogel (Figure 1a) shows uniform morphology of randomly-arranged sheet-like structures of graphene. The SEM image of $\mathrm{V}_{2} \mathrm{O}_{5}$ aerogel presented in Figure $1 \mathrm{~b}$ displays 3-D networks of rod-like interconnected vanadia particles, which is further verified by the TEM image in Figure 1c. The image in Figure 1c suggests that the building blocks of $\mathrm{V}_{2} \mathrm{O}_{5}$ aerogel were rod-like structures of typical length approximately $300 \mathrm{~nm}$ and diameter several tens of nanometers. Such rod-like structures with typical length $1 \mu \mathrm{m}$ were reported earlier [16]. The TEM image of the hybrid aerogel $r G O-\mathrm{V}_{2} \mathrm{O}_{5}-0.82$ in Figure $1 \mathrm{~d}$ indicates the presence of both rod-like structure of $\mathrm{V}_{2} \mathrm{O}_{5}$ as in Figure 1c, and the layers of thin sheets of graphene, as seen in Figure 1a. We attribute such a hybrid aerogel structure to the specific gelation process used in Method I.
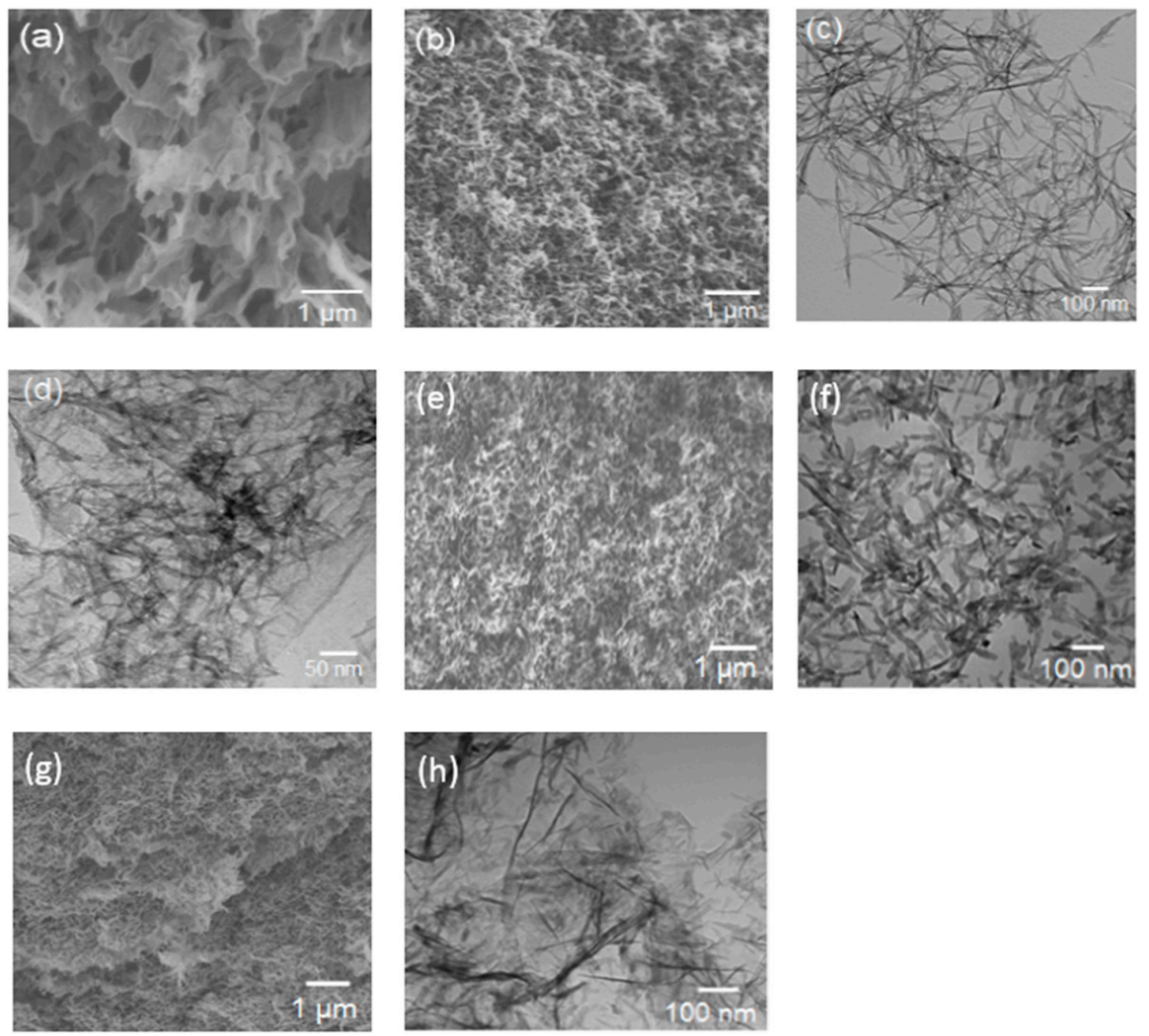

Figure 1. (a-d) correspond to Method I: SEM images of (a) rGO aerogel and (b) $\mathrm{V}_{2} \mathrm{O}_{5}$ aerogel; TEM images of (c) $\mathrm{V}_{2} \mathrm{O}_{5}$ aerogel and (d) $\mathrm{rGO}-\mathrm{V}_{2} \mathrm{O}_{5}-0.82$ hybrid aerogel. (e-h) correspond to Method II. (e) SEM and (f) TEM images of $\mathrm{V}_{2} \mathrm{O}_{5}$ aerogel; (g) SEM image of $\mathrm{V}_{2} \mathrm{O}_{5}$-rGO-6 hybrid aerogel; and (h) TEM image of $\mathrm{V}_{2} \mathrm{O}_{5}$-rGO-6 hybrid aerogel. 
The composition of the as prepared hybrid aerogels was quantitatively determined from the TGA traces generated in air. In Figure S2a, the TGA traces revealed the following trends: gradual weight loss at just above room temperature due to a loss of moisture; weight reduction at close to $200^{\circ} \mathrm{C}$ due to the removal of bound water; and the more dramatic weight loss between $300{ }^{\circ} \mathrm{C}$ and $350{ }^{\circ} \mathrm{C}$ due to the decomposition of the organic groups on graphene [17]. The steep decline in specimen weight at $400-430^{\circ} \mathrm{C}$ was due to burning off of graphene [11]. The weight gain after $430^{\circ} \mathrm{C}$ is attributed to oxidation of $\mathrm{V}^{4+}$ ions to $\mathrm{V}^{5+}$ ions. The differences of the residual weights of the hybrid aerogel and that of the $\mathrm{V}_{2} \mathrm{O}_{5}$ aerogel with the same amount of vanadium isopropoxide in the formulations were used to determine the approximate graphene content in the hybrid aerogels. The graphene contents were found to be $29 \mathrm{wt} \%, 24 \mathrm{wt} \%$, and $17 \mathrm{wt} \%$ respectively for hybrid aerogels $\mathrm{rGO}-\mathrm{V}_{2} \mathrm{O}_{5}-0.64$, rGO- $\mathrm{V}_{2} \mathrm{O}_{5}-0.82$, and $\mathrm{rGO}-\mathrm{V}_{2} \mathrm{O}_{5}-1$.

The crystal structure of the samples, especially the basal spacing of graphene particles, was inferred from the X-ray diffraction (XRD) patterns as shown in Figure 2. The basal spacing of GO was found to be $0.91 \mathrm{~nm}$ which is much larger than that of natural graphite $(0.33 \mathrm{~nm})$, indicating that chemical oxidation of graphite to GO was complete in these materials and that the interlayer distance was expanded [18]. In the case of rGO aerogel, the XRD pattern shows a broad peak at around $24^{\circ}$. In addition, the peak at $9.8^{\circ}$ corresponding to (001) plane of GO is absent in Figure 2a. This indicates that the method of reduction of GO to graphene using L-ascorbic acid was successful.
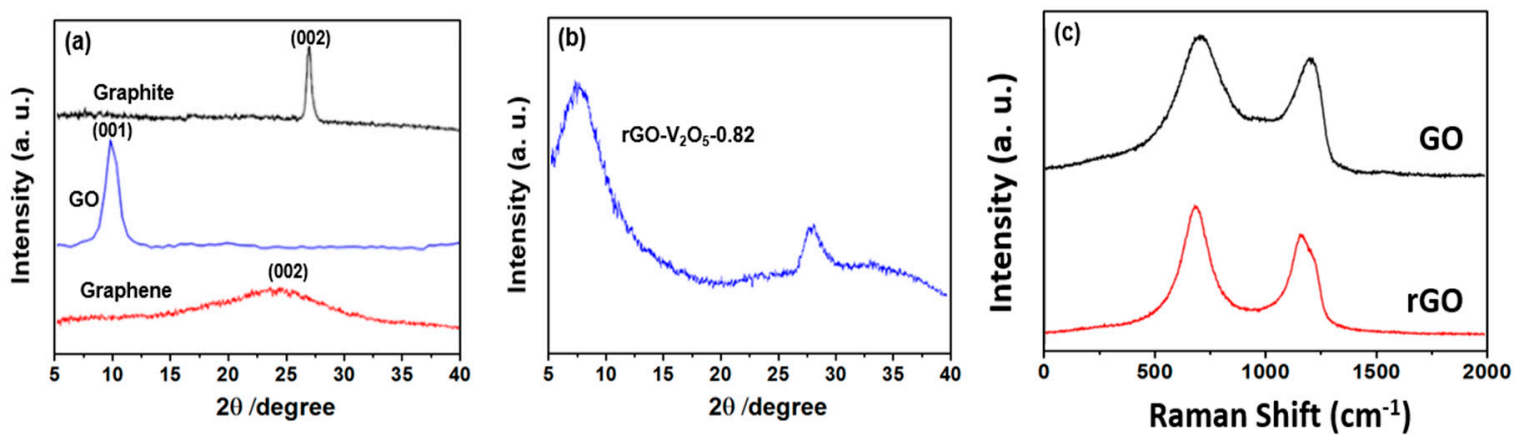

Figure 2. (a,b) XRD patterns of graphite, GO, graphene, and $\mathrm{rGO}-\mathrm{V}_{2} \mathrm{O}_{5}-0.82$ hybrid aerogel; and (c) Raman spectra of GO and rGO.

The XRD pattern of the rGO- $\mathrm{V}_{2} \mathrm{O}_{5}-0.82$ hybrid aerogel revealed only two reflection peaks at around $7.4^{\circ}$ and $27.9^{\circ}$, and the low intensity of the peaks suggests a small degree of crystalline order [19]. In view of previous work [20,21], the (001) peak at $7.4^{\circ}$ corresponds to the layer stacking of $\mathrm{V}_{2} \mathrm{O}_{5}(\mathrm{~d}=1.19 \mathrm{~nm})[22,23]$. The absence of a graphene peak in the XRD patterns of hybrid aerogels indicates that restacking of graphene sheets did not occur in hybrid aerogels and that graphene was present mostly as single sheets [24]. The FTIR spectra shown in Figure S3 suggests the chemical structures of GO, rGO, and the hybrid aerogels.

Raman spectroscopy was used to determine the quality of graphene by analyzing the intensity ratio of the D- and G-bands. The D-band results from the disorder-induced mode reflecting structural defects and the G-band is associated with the $\mathrm{E}_{2 \mathrm{~g}}$ mode from $\mathrm{sp}^{2}$-hybridized carbon domains [25]. The intensity ratio $\mathrm{I}_{\mathrm{D}} / \mathrm{I}_{\mathrm{G}}$ reflects the disorder degree of carbon materials [26]. The Raman spectra of GO and rGO aerogel are shown in Figure 2c. There are two obvious peaks at around $1357 \mathrm{~cm}^{-1}$ and $1608 \mathrm{~cm}^{-1}$ in the Raman spectrum of GO corresponding to the D-band and G-band, respectively. The Raman spectrum of rGO aerogel also shows the D- (at $1343 \mathrm{~cm}^{-1}$ ) and G-band (at $1585 \mathrm{~cm}^{-1}$ ). The $\mathrm{I}_{\mathrm{D}} / \mathrm{I}_{\mathrm{G}}$ ratio of rGO aerogel is 1.24 which is greater than that of $\mathrm{GO}(1.15)$ indicating a reduction of the average size of the $\mathrm{sp}^{2}$ domains [27] when the oxygen groups were removed during the reduction process of GO. In addition, the width of the half-maximum of the G-band was reduced, which suggests a high graphitization degree of rGO aerogel [28]. 
The presence of platelet-type graphene particles and rod-like vanadia particles in the hybrid aerogels presents several interesting scenarios in terms of solid surface area and pore size distribution. Barrett-Joyner-Halenda (BJH) pore size distributions of rGO aerogel and $\mathrm{rGO}^{-} \mathrm{V}_{2} \mathrm{O}_{5}-0.82$ hybrid aerogel are presented in Figure S4a,b. These were obtained from nitrogen adsorption-desorption isotherms shown in Figure S5. As is evident, the isotherms in Figure S5 are type IV, indicating mesoporous structures. Both samples show mesopores with distinct pore size distribution, as seen in Figure S4. In the case of rGO aerogel, the predominant pores are $4 \mathrm{~nm}$ and $60 \mathrm{~nm}$, while those for rGO- $\mathrm{V}_{2} \mathrm{O}_{5}-0.82$ hybrid aerogel are $4 \mathrm{~nm}$ and $40 \mathrm{~nm}$, the latter due to the presence of $\mathrm{V}_{2} \mathrm{O}_{5}$. The BET specific surface area of $\mathrm{rGO}-\mathrm{V}_{2} \mathrm{O}_{5}$ hybrid aerogels are generally lower than that of rGO aerogel $\left(641 \mathrm{~m}^{2} / \mathrm{g}\right)$, e.g., $396,348,299 \mathrm{~m}^{2} / \mathrm{g}$, respectively, for hybrid aerogel specimens $\mathrm{rGO}-\mathrm{V}_{2} \mathrm{O}_{5}-0.64$, rGO- $\mathrm{V}_{2} \mathrm{O}_{5}-0.82$, and $\mathrm{rGO}-\mathrm{V}_{2} \mathrm{O}_{5}-1$. Note that the specific surface area of $\mathrm{V}_{2} \mathrm{O}_{5}$ aerogel $\left(254 \mathrm{~m}^{2} / \mathrm{g}\right)$ is much smaller than that of $\mathrm{rGO}$ aerogel.

The specific capacitance of the electrodes fabricated using $\mathrm{V}_{2} \mathrm{O}_{5}$ aerogel, rGO aerogel, and $\mathrm{V}_{2} \mathrm{O}_{5}$-rGO hybrid aerogels were determined from galvanostatic charge/discharge test data. The values of specific capacitance are shown in Figure 3a. We find that the specific capacitance of the rGO- $\mathrm{V}_{2} \mathrm{O}_{5}-0.82$ hybrid aerogel calculated from charge/discharge curves are much higher $(203 \mathrm{~F} / \mathrm{g})$, compared to the rGO aerogel $(105 \mathrm{~F} / \mathrm{g})$ and the $\mathrm{V}_{2} \mathrm{O}_{5}$ aerogel $(132 \mathrm{~F} / \mathrm{g})$. In view of this, the electrochemical performance the $\mathrm{rGO}-\mathrm{V}_{2} \mathrm{O}_{5}-0.82$ hybrid aerogel was further investigated. In Figure $3 \mathrm{~b}$, the $\mathrm{CV}$ curve of the rGO aerogel exhibits an almost rectangular shape suggesting the EDLC characteristic [3]. In the case of the $\mathrm{rGO}-\mathrm{V}_{2} \mathrm{O}_{5}-0.82$ hybrid aerogel, a pair of redox peaks are observed with a larger area than the $\mathrm{V}_{2} \mathrm{O}_{5}$ aerogel and the graphene aerogel under the same scanning rate. These indicate that the specific capacitance of the rGO- $\mathrm{V}_{2} \mathrm{O}_{5}-0.82$ hybrid aerogel is higher than both the rGO and $\mathrm{V}_{2} \mathrm{O}_{5}$ aerogels along with a Faradaic redox reaction occurring during the charge/discharge process (Figure 3c) [3]. Furthermore, for the hybrid aerogel system, the redox peak is more well-defined, which implies that the presence of graphene improves the utilization of $\mathrm{V}_{2} \mathrm{O}_{5}$ and, therefore, contributes pseudo-capacitance to the overall capacitance. The CV curves of the $\mathrm{rGO}-\mathrm{V}_{2} \mathrm{O}_{5}-0.82$ hybrid aerogel at varied scan rates (Figure 3d) show a regular and symmetric shape to zero-current line indicating an excellent electrochemical reversibility due to the synergetic effect of EDLC and pseudo-capacitor. The Nyquist plot shown in Figure 3e reveals that rGO aerogel shows an almost ideal EDLC feature with a nearly vertical straight line along the imaginary axis in the low frequency region. Additionally, for the rGO- $\mathrm{V}_{2} \mathrm{O}_{5}-0.82$ hybrid aerogel, a stronger vertical line than the $\mathrm{V}_{2} \mathrm{O}_{5}$ aerogel are observed, which is closer to the line for the rGO aerogel. Moreover, the charge transfer resistance $\left(\mathrm{R}_{\mathrm{CT}}\right)$ measured by the diameter of the semicircle in the high-frequency region also reflects the capacitive property [29]. The calculated values of $\mathrm{R}_{\mathrm{CT}}$ for the $\mathrm{rGO}$ aerogel, the $\mathrm{V}_{2} \mathrm{O}_{5}$ aerogel, and the $\mathrm{rGO}-\mathrm{V}_{2} \mathrm{O}_{5}-0.82$ hybrid aerogel are $0.4 \Omega, 3.7 \Omega$, and $1.7 \Omega$, respectively. These results indicate that the combination of $\mathrm{V}_{2} \mathrm{O}_{5}$ and graphene improves the conductivity of the electrode materials and minimizes the ion transportation path.

The cycle stability was tested at $10 \mathrm{~A} / \mathrm{g}$ of charge/discharge for 1000 cycles (Figure 3f). It can be seen that the degradation of specific capacitance of the rGO aerogel starts from 100 cycles with a consistent, but small, reduction until 1000 cycles exhibiting a characteristic of EDLC. Moreover, the $\mathrm{V}_{2} \mathrm{O}_{5}$ aerogel shows a quite poor cycle stability due to the structural damage caused by the mechanical stress induced by the ion intercalation-de-intercalation phenomena during the charge-discharge process [30] and dissolution of vanadium oxide [31]. However, the cycle stability of the $\mathrm{rGO}-\mathrm{V}_{2} \mathrm{O}_{5}-0.82$ hybrid aerogel obviously improved, e.g., $73 \%$ of initial capacitance. This was achieved due to the presence of graphene nanosheets that were able to withstand the structural changes during the charge-discharge process. 

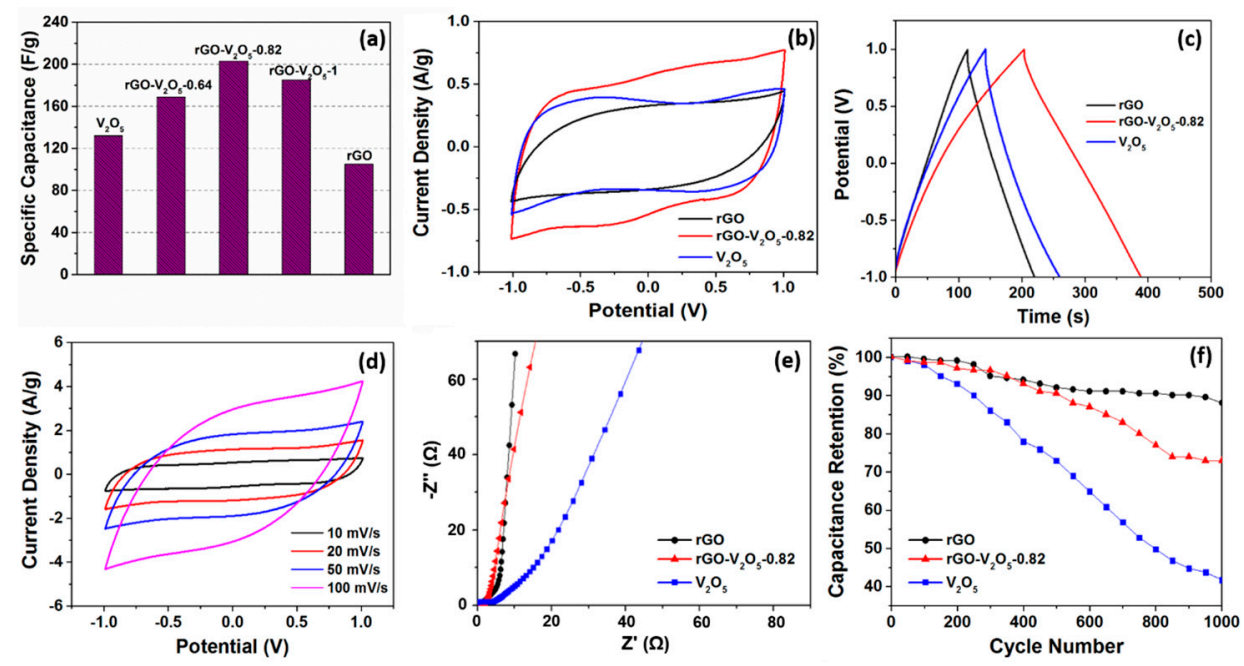

Figure 3. (a) Summary of specific capacitance of a series hybrid aerogels prepared by Method I as compared with pure $\mathrm{V}_{2} \mathrm{O}_{5}$ and rGO aerogels; (b) cyclic voltammetry curves of the rGO- $\mathrm{V}_{2} \mathrm{O}_{5}-0.82$ hybrid aerogel as compared with pure $\mathrm{V}_{2} \mathrm{O}_{5}$ and $\mathrm{rGO}$ aerogels at a scan rate of $10 \mathrm{mV} / \mathrm{s}$; (c) galvanostatic charge/discharge curves of $\mathrm{rGO}$ and $\mathrm{V}_{2} \mathrm{O}_{5}$ aerogels and the $\mathrm{rGO}-\mathrm{V}_{2} \mathrm{O}_{5}-0.82$ hybrid aerogel at a current density of $1 \mathrm{~A} / \mathrm{g}$; (d) $\mathrm{CV}$ curves of the $\mathrm{rGO}-\mathrm{V}_{2} \mathrm{O}_{5}-0.82$ hybrid aerogel at a varied scan rate; (e) electrochemical impedance spectra measured at a frequency of 0.01 HZ-100 kHZ for the rGO aerogel, the $\mathrm{V}_{2} \mathrm{O}_{5}$ aerogel, and the $\mathrm{rGO}-\mathrm{V}_{2} \mathrm{O}_{5}-0.82$ hybrid aerogel; and (f) cycle stability of the rGO aerogel, the $\mathrm{V}_{2} \mathrm{O}_{5}$ aerogel, and the $\mathrm{rGO}-\mathrm{V}_{2} \mathrm{O}_{5}-0.82$ hybrid aerogel.

\subsection{Hybrid Aerogels from One-Pot Synthesis via Method II}

The SEM and TEM images (Figure 1e,f) of the heat-treated $\mathrm{V}_{2} \mathrm{O}_{5}$ aerogel reveal a randomly-arranged rod-like morphology with lengths less than $100 \mathrm{~nm}$ and diameters of several nanometers. These dimensions are much lower than those of the $\mathrm{V}_{2} \mathrm{O}_{5}$ aerogel and can be attributed to crystallization at the time of thermal treatment. The $\mathrm{V}_{2} \mathrm{O}_{5}-\mathrm{rGO}-6$ hybrid aerogel displays a morphology of crumpled graphene sheets where the growth of $\mathrm{V}_{2} \mathrm{O}_{5}$ nanofibers is apparent (Figure 1g,h). We note that GO particles were well-dispersed in water and the $\mathrm{V}_{2} \mathrm{O}_{5}$ nanofibers possibly grew on the surfaces of graphene sheets. The morphology of the $\mathrm{V}_{2} \mathrm{O}_{5}-\mathrm{rGO}-6$ hybrid aerogel further confirms the interaction of VO oligomers with GO sheets in the hydrolysis step.

Figure S2b shows the TGA traces of the samples conducted in air with a heating rate of $10^{\circ} \mathrm{C} / \mathrm{min}$. The weight loss of the $\mathrm{V}_{2} \mathrm{O}_{5}$ aerogel before $150^{\circ} \mathrm{C}$ is due to the evaporation of absorbed moisture. In the case of the $\mathrm{V}_{2} \mathrm{O}_{5}-\mathrm{rGO}$ hybrid aerogels, there is gradual weight loss from around room temperature to about $400{ }^{\circ} \mathrm{C}$, suggesting that such loss was due to the evaporation of moisture and decomposition of the oxygen-containing groups of GO. In addition, for all hybrid aerogels, a sharp weight reduction occurred in the range of $400^{\circ} \mathrm{C}$ to $480{ }^{\circ} \mathrm{C}$, due to the burning of graphene [32]. The graphene weight percent in hybrid aerogels $\mathrm{V}_{2} \mathrm{O}_{5}-\mathrm{rGO}-2, \mathrm{~V}_{2} \mathrm{O}_{5}-\mathrm{rGO}-4$, and $\mathrm{V}_{2} \mathrm{O}_{5}-\mathrm{rGO}-6$ was estimated to be $12 \%, 17 \%$, and $23 \%$, respectively.

The X-ray diffraction patterns of the heat-treated $\mathrm{V}_{2} \mathrm{O}_{5}$ aerogel and $\mathrm{V}_{2} \mathrm{O}_{5}$-rGO hybrid aerogels (Figure $4 a, b$ ) were examined to determine if the heat treatment step used for thermal reduction of GO also caused substantial changes in the crystal structures of the hybrid materials. In Figure $4 \mathrm{~b}$, the XRD patterns of a series of $\mathrm{V}_{2} \mathrm{O}_{5}$-rGO hybrid aerogels exhibit (200), (001), (110), (301), and (310) reflection peaks corresponding to orthorhombic crystalline $\mathrm{V}_{2} \mathrm{O}_{5}$ (JCPDS No. 41-1426) at the same position as in the case of $\mathrm{V}_{2} \mathrm{O}_{5}$ aerogel (Figure 4a). These indicate that the $\mathrm{V}_{2} \mathrm{O}_{5}-\mathrm{rGO}$ hybrid aerogels were partly crystalline due to the thermal treatment. Additionally, in comparison to $\mathrm{V}_{2} \mathrm{O}_{5}$ aerogel, no additional peaks are detected in the hybrid aerogels, which indicates high purity of the $\mathrm{V}_{2} \mathrm{O}_{5}$ parts in the aerogel. The intensity of the $\mathrm{XRD}$ reflection peaks shows reduction with an increase of the amount of graphene in the $\mathrm{V}_{2} \mathrm{O}_{5}$-rGO hybrid aerogels while the peak positions remain the same. This implies that the $\mathrm{V}_{2} \mathrm{O}_{5}$ 
layered structure was maintained despite the presence of graphene, although, graphene influenced its crystal formation. The XRD patterns only show $\mathrm{V}_{2} \mathrm{O}_{5}$ reflection peaks in the $\mathrm{V}_{2} \mathrm{O}_{5}$-rGO hybrid aerogels, which indicates that $\mathrm{V}_{2} \mathrm{O}_{5}$ nanofibers prevented restacking of graphene nanosheets [22].
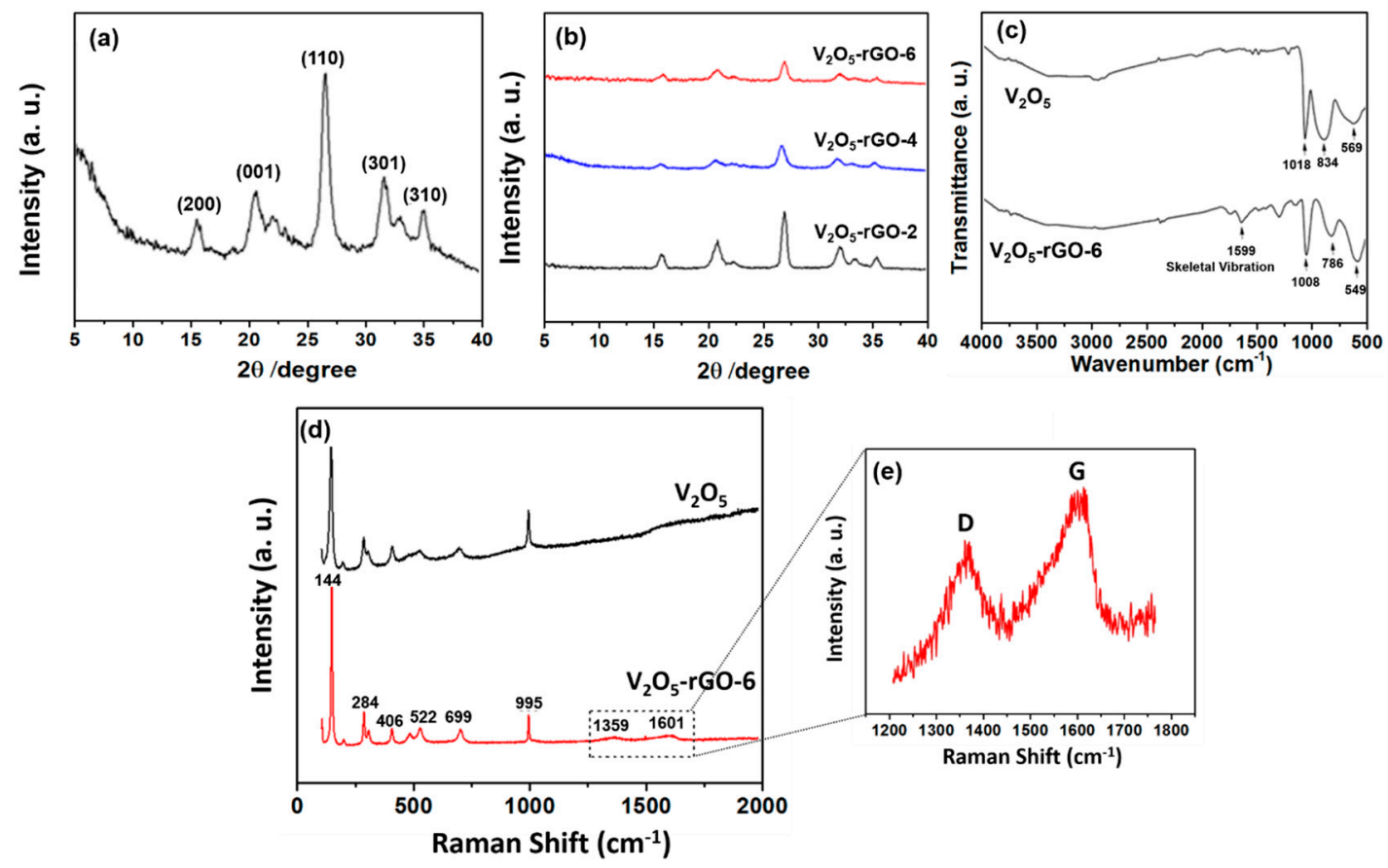

Figure 4. (a) XRD patterns of the $\mathrm{V}_{2} \mathrm{O}_{5}$ aerogel; (b) XRD patterns of the $\mathrm{V}_{2} \mathrm{O}_{5}$-rGO hybrid aerogels with varying weight compositions; (c) FTIR spectra of the $\mathrm{V}_{2} \mathrm{O}_{5}$ and $\mathrm{V}_{2} \mathrm{O}_{5}$-rGO-6 hybrid aerogels; (d,e) Raman spectra of the $\mathrm{V}_{2} \mathrm{O}_{5}$ aerogel and the $\mathrm{V}_{2} \mathrm{O}_{5}$-rGO-6 hybrid aerogel.

Figure 4c shows FTIR spectra to verify if the thermal reduction method successfully reduced GO to graphene. The characteristic peaks in FTIR spectra at 569, 834, and $1018 \mathrm{~cm}^{-1}$ of the $\mathrm{V}_{2} \mathrm{O}_{5}$ aerogel correspond to triply-coordinated oxygen (chain oxygen) bonds in vanadium oxide, doubly-coordinated oxygen (bridge oxygen) bonds, and stretching vibration of terminal oxygen bonds $(\mathrm{V}=\mathrm{O})$, respectively [24]. For $\mathrm{V}_{2} \mathrm{O}_{5}-\mathrm{rGO}-6$ hybrid aerogel, the vanadium oxide characteristic peaks shifted, indicating an interaction of $\mathrm{V}_{2} \mathrm{O}_{5}$ nanofibers and graphene nanosheets [33]. The bond at $1599 \mathrm{~cm}^{-1}$ is observed clearly due to the skeletal vibration of graphene [34].

In Raman spectra shown in Figure 4d,e, the peaks at 144, 284, 406, 522, 699, and $995 \mathrm{~cm}^{-1}$ can be observed in both the $\mathrm{V}_{2} \mathrm{O}_{5}$ aerogel and the $\mathrm{V}_{2} \mathrm{O}_{5}$-rGO-6 hybrid aerogel, which correspond to the following signatures: skeleton bending vibration of the $\mathrm{V}-\mathrm{O}-\mathrm{V}$ bonds $\left(144 \mathrm{~cm}^{-1}\right)$, bending vibrations of the $\mathrm{V}=\mathrm{O}$ bonds $\left(284 \mathrm{~cm}^{-1}\right)$, bending vibrations of bridge oxygen bonds $\left(406 \mathrm{~cm}^{-1}\right)$, stretching vibrations of triply-coordinated oxygen bonds $\left(522 \mathrm{~cm}^{-1}\right)$, stretching vibrations of doubly-coordinated oxygen $\left(699 \mathrm{~cm}^{-1}\right)$, and in-phase stretching vibrational of $\mathrm{V}=\mathrm{O}$ bonds $\left(995 \mathrm{~cm}^{-1}\right)$ [13]. The two peaks at 1359 and $1601 \mathrm{~cm}^{-1}$ in the $\mathrm{V}_{2} \mathrm{O}_{5}$-rGO-6 hybrid aerogel belong to the D- and G-bands of graphene, which suggests a complete reduction of $\mathrm{GO}$ and the presence of graphene.

The $\mathrm{BJH}$ pore distribution (Figure $\mathrm{S} 4 \mathrm{c}$ ) of $\mathrm{V}_{2} \mathrm{O}_{5}$-rGO hybrid aerogels exhibits slightly different distribution from the $\mathrm{V}_{2} \mathrm{O}_{5}$ aerogel, especially the $\mathrm{V}_{2} \mathrm{O}_{5}$-rGO-6 hybrid aerogel shows a peak at $40 \mathrm{~nm}$. This pore size distribution of the two types of samples might have some effect on the electrochemical property because the mesopores provide more accessibility for ion transportation [35]. The BET-specific surface areas of the samples are listed in Tables 1 and 2.

The BET-specific surface area of the $\mathrm{V}_{2} \mathrm{O}_{5}-\mathrm{rGO}-6$ hybrid aerogel $\left(392 \mathrm{~cm}^{2} / \mathrm{g}\right)$ is much larger than the $\mathrm{V}_{2} \mathrm{O}_{5}$ aerogel $\left(213 \mathrm{~cm}^{2} / \mathrm{g}\right)$, which resulted from the presence of high surface area graphene nanosheets. This has the potential to provide much higher capacity for energy storage. Note in this case that the surface area of $\mathrm{V}_{2} \mathrm{O}_{5}$ aerogel listed in Table 2 is lower than that reported in Table 1. After annealing, the pore structure of the $\mathrm{V}_{2} \mathrm{O}_{5}$ aerogel changed due to the oxidation of $\mathrm{VO}_{\mathrm{x}}$ and 
partial crystallization of $\mathrm{V}_{2} \mathrm{O}_{5}$. Thus, the BET-specific surface area of the heat-treated $\mathrm{V}_{2} \mathrm{O}_{5}$ aerogel reduced to $213 \mathrm{~m}^{2} \cdot \mathrm{g}^{-1}$. For a supercapacitor, especially for hybrid electrodes, the surface area serves as a significant factor for charge storage that provides space for Faradaic redox reactions to produce pseudocapacitance. In this way, the large specific surface area of the $\mathrm{V}_{2} \mathrm{O}_{5}-\mathrm{rGO}$ hybrid aerogel favors capacitance.

Table 1. BET-specific surface area of the $\mathrm{V}_{2} \mathrm{O}_{5}$, graphene, and $\mathrm{V}_{2} \mathrm{O}_{5}$-rGO hybrid aerogels prepared by Method I.

\begin{tabular}{cccccc}
\hline Sample & $\mathrm{V}_{\mathbf{2}} \mathbf{O}_{\mathbf{5}}$ & Graphene & $\mathrm{V}_{\mathbf{2}} \mathbf{O}_{\mathbf{5}}$-rGO-0.64 & $\mathrm{V}_{\mathbf{2}} \mathbf{O}_{5}$-rGO-0.82 & $\mathrm{V}_{\mathbf{2}} \mathbf{O}_{5}-\mathrm{rGO}-\mathbf{1}$ \\
\hline $\mathrm{SSA} / \mathrm{m}^{2} \cdot \mathrm{g}^{-1}$ & 254 & 641 & 396 & 348 & 299 \\
\hline
\end{tabular}

Table 2. BET-specific surface area of the $\mathrm{V}_{2} \mathrm{O}_{5}$ aerogel and $\mathrm{V}_{2} \mathrm{O}_{5}-\mathrm{rGO}$ hybrid aerogels prepared by Method II.

\begin{tabular}{ccccc}
\hline Sample & $\mathrm{V}_{\mathbf{2}} \mathrm{O}_{\mathbf{5}}$ & $\mathrm{V}_{\mathbf{2}} \mathrm{O}_{5}$-rGO-2 & $\mathrm{V}_{\mathbf{2}} \mathrm{O}_{5}$-rGO-4 & $\mathrm{V}_{\mathbf{2}} \mathrm{O}_{5}$-rGO-6 \\
\hline $\mathrm{SSA} / \mathrm{m}^{2} \cdot \mathrm{g}^{-1}$ & 213 & 282 & 357 & 392 \\
\hline
\end{tabular}

The specific capacitance was obtained from the data of charge-discharge curves and calculated from Equation (1). The galvanostatic charge/discharge curves of the different $\mathrm{V}_{2} \mathrm{O}_{5}-\mathrm{rGO}$ hybrid aerogels are shown in Figure 5a. It can be seen that the specific capacitance of the $\mathrm{V}_{2} \mathrm{O}_{5}$-rGO hybrid aerogel is generally higher than the $\mathrm{V}_{2} \mathrm{O}_{5}$ aerogel $(98 \mathrm{~F} / \mathrm{g}$ ). In addition, an increase in specific capacitance is observed for materials with higher content of graphene in the $\mathrm{V}_{2} \mathrm{O}_{5}-\mathrm{rGO}$ hybrid aerogels. The specific capacitance of a series of $\mathrm{V}_{2} \mathrm{O}_{5}-\mathrm{rGO}$ hybrid aerogels, respectively, for the $\mathrm{V}_{2} \mathrm{O}_{5}-\mathrm{rGO}-2$, $\mathrm{V}_{2} \mathrm{O}_{5}-\mathrm{rGO}-4$, and $\mathrm{V}_{2} \mathrm{O}_{5}-\mathrm{rGO}-6$ hybrid aerogels are 163,202 , and $272 \mathrm{~F} / \mathrm{g}$, which are summarized in Figure $5 b$. This tendency is led by a synergetic effect of $\mathrm{V}_{2} \mathrm{O}_{5}$ and graphene, in which graphene enhances the conductivity and increases the specific surface area of the $\mathrm{V}_{2} \mathrm{O}_{5}$-rGO hybrid aerogels in order to promote better utilization of $\mathrm{V}_{2} \mathrm{O}_{5}$.
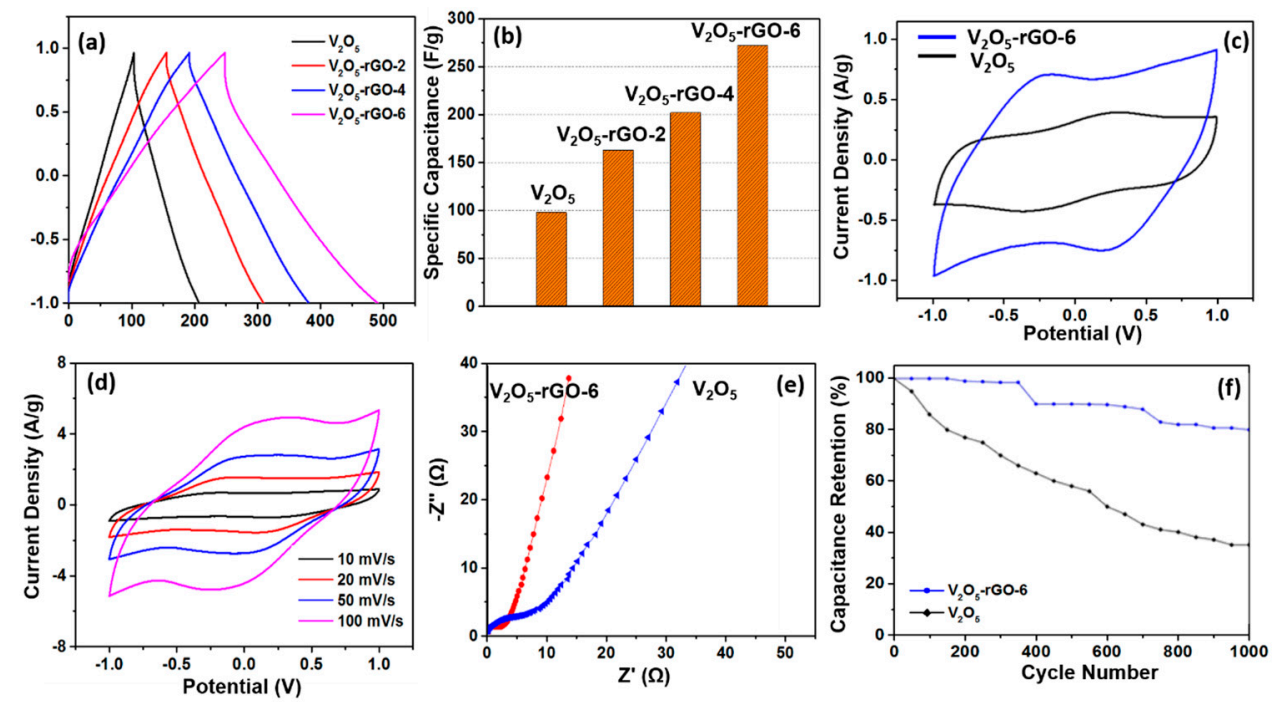

Figure 5. (a) Galvanostatic charge/discharge curves of the $\mathrm{V}_{2} \mathrm{O}_{5}$ and $\mathrm{V}_{2} \mathrm{O}_{5}$-rGO hybrid aerogels with different ratios at a current density of $1 \mathrm{~A} / \mathrm{g}$; (b) summary of specific capacitance of the $\mathrm{V}_{2} \mathrm{O}_{5}$ and $\mathrm{V}_{2} \mathrm{O}_{5}$-rGO hybrid aerogels; (c) $\mathrm{CV}$ curves of the $\mathrm{V}_{2} \mathrm{O}_{5}$ and $\mathrm{V}_{2} \mathrm{O}_{5}$-rGO-6 hybrid aerogel at a scan rate of $10 \mathrm{mV} / \mathrm{s}$; (d) CV curves of the $\mathrm{V}_{2} \mathrm{O}_{5}$-rGO-6 hybrid aerogel at varying scan rates; (e) EIS of the $\mathrm{V}_{2} \mathrm{O}_{5}$ and $\mathrm{V}_{2} \mathrm{O}_{5}$-rGO-6 hybrid aerogel measured at a frequency of $0.01 \mathrm{HZ}-100 \mathrm{kHZ}$; and (f) cycle stability of the $\mathrm{V}_{2} \mathrm{O}_{5}$ and $\mathrm{V}_{2} \mathrm{O}_{5}-\mathrm{rGO}-6$ hybrid aerogels tested at a current density of $10 \mathrm{~A} / \mathrm{g}$. 
Since the specific capacitance of the $\mathrm{V}_{2} \mathrm{O}_{5}-\mathrm{rGO}-6$ hybrid aerogel is the highest among the three materials studied, further investigation of its electrochemical performance was conducted. The cyclic voltammetry curves of both samples are shown in Figure 5c. The shape of CV curves of both materials is symmetrical, suggesting an electrochemical reversibility. These curves deviated from an ideal rectangle indicating the Faradic pseudocapacitance. A pair of redox peaks of potentials at around $0.32 \mathrm{~V}$ and $0.30 \mathrm{~V}$ resulted from the transformation between $\mathrm{V}^{5+}$ and $\mathrm{V}^{4+}$. However, the $\mathrm{CV}$ curve of the $\mathrm{V}_{2} \mathrm{O}_{5}$-rGO-6 hybrid aerogel shows undefined redox peaks, which are possibly caused by the EDLC contribution by graphene. This result further confirms the synergetic effect of the double-layer capacitance and pseudocapacitance [36]. The area of the $\mathrm{CV}$ curve of the $\mathrm{V}_{2} \mathrm{O}_{5}$-rGO-6 hybrid aerogel is much larger than that of the $\mathrm{V}_{2} \mathrm{O}_{5}$ aerogel, and this also confirms a higher specific capacitance of the $\mathrm{V}_{2} \mathrm{O}_{5}$-rGO-6 hybrid aerogel. The $\mathrm{CV}$ curves of the $\mathrm{V}_{2} \mathrm{O}_{5}$-rGO-6 hybrid aerogel at different scan rates are shown in Figure 5d in order to further study the capacitive performance. As the scan rate increases, the quasi-rectangular shape of the $\mathrm{CV}$ curves is affected, although the shape of the curves remains mirror-symmetric with zero-current line even at the high scan rate of $100 \mathrm{mV} / \mathrm{s}$. This result implies a high rate performance and good capacitive reversibility [37]. Note that the specific capacitance of the $\mathrm{V}_{2} \mathrm{O}_{5}-\mathrm{rGO}-6$ hybrid aerogel is much higher than that of graphene-templated $\mathrm{rGO}-\mathrm{V}_{2} \mathrm{O}_{5}-0.82$ hybrid aerogel $\left(203 \mathrm{~F} \cdot \mathrm{g}^{-1}\right)$ produced in Method I with a similar amount of graphene, even if $\mathrm{V}_{2} \mathrm{O}_{5}$ is partly crystalline due to the thermal reduction for the $\mathrm{V}_{2} \mathrm{O}_{5}-\mathrm{rGO}-6$ hybrid aerogel.

It can be concluded from the data presented up to this point that the preparation method strongly influenced the structure-properties relationships and the final electrochemical performance. In Method I, the capillary force contributed to selective localization of $\mathrm{V}_{2} \mathrm{O}_{5}$ on the graphene nanosheets. Additionally, the unavoidable diffusion gradient quite possibly led to a heterogeneous dispersion of $\mathrm{V}_{2} \mathrm{O}_{5}$ within the rGO aerogel produced by Method I. In Method II, the recombination of $\mathrm{V}_{2} \mathrm{O}_{5}$ and graphene in hybrid aerogels was easily accomplished and enhanced by the coordination bonds between $\mathrm{V}_{2} \mathrm{O}_{5}$ and graphene nanosheets that are much stronger than the capillary force in Method I. Meanwhile, the uniform mixing of $\mathrm{V}_{2} \mathrm{O}_{5}$ and graphene also produces a homogeneous hybrid structure in Method II. In addition, the BET-specific surface area of the $\mathrm{V}_{2} \mathrm{O}_{5}-\mathrm{rGO}-6$ hybrid aerogel is greater than the $\mathrm{rGO}-\mathrm{V}_{2} \mathrm{O}_{5}-0.82$ hybrid aerogel, suggesting that there is more capacity for energy storage in hybrid materials produced by Method II. These factors answer why the hybrid aerogels from Method I exhibit inferior electrochemical performance than hybrid aerogels produced by Method II.

The Nyquist plots of EIS of $\mathrm{V}_{2} \mathrm{O}_{5}$ aerogel are shown in Figure 5e. The corresponding equivalent circuit is presented in Figure S6. In comparison, the $\mathrm{V}_{2} \mathrm{O}_{5}-\mathrm{rGO}-6$ hybrid aerogel has more vertical lines parallel to the imaginary axis than the $\mathrm{V}_{2} \mathrm{O}_{5}$ aerogel, which indicates that the electrical conductivity of the hybrid aerogel was improved or the accessibility of ions in the electrolyte was enhanced due to the combination of the structures from graphene and $\mathrm{V}_{2} \mathrm{O}_{5}$ and, therefore, exhibited a behavior more closely to that of an ideal supercapacitor. The cycle stabilities of the $\mathrm{V}_{2} \mathrm{O}_{5}$ aerogel and the $\mathrm{V}_{2} \mathrm{O}_{5}-\mathrm{rGO}-6$ hybrid aerogel were characterized by a charge/discharge test over 1000 cycles at a constant current density of $10 \mathrm{~A} / \mathrm{g}$ shown in Figure $5 \mathrm{f}$. This indicates clearly that the capacitance retention of the $\mathrm{V}_{2} \mathrm{O}_{5}$-rGO-6 hybrid aerogel was $80 \%$ after 1000 operation cycles, while the capacitance retention of the $\mathrm{V}_{2} \mathrm{O}_{5}$ aerogel was only $35 \%$ of the initial specific capacitance. The low capacitance retention of the $\mathrm{V}_{2} \mathrm{O}_{5}$ aerogel can be attributed to the structural damage caused by the insertion and desertion of electrolyte ions during the charge/discharge process [38] and two clear drops after 350th and 700th cycles could be possibly caused by the large structural changes of $\mathrm{V}_{2} \mathrm{O}_{5}$. According to published literature, pure $\mathrm{V}_{2} \mathrm{O}_{5}$ shows very poor cycle stability up to only 100 cycles in aqueous electrolyte [19]. Obviously, the addition of graphene improved the cycle stability for the materials developed in this work due to its electroactive property.

\section{Conclusions}

This study considered two methods for the preparation of hybrid aerogels of $\mathrm{V}_{2} \mathrm{O}_{5}$ and rGO. The specific capacitance of hybrid materials prepared by Method I increased to $202 \mathrm{~F} / \mathrm{g}$ with $23 \mathrm{wt} \%$ graphene. Such improved capacitance is due to the synergy derived from the higher electrical conductivity of graphene, the greater contact between the electrode and electrolyte due to higher 
surface area, and the pseudocapacitance of $\mathrm{V}_{2} \mathrm{O}_{5}$. The hybrid materials prepared by one-pot synthesis route in Method II produced much higher capacitance of $272 \mathrm{~F} / \mathrm{g}$ at $23 \mathrm{wt} \%$ graphene content and exhibited improved cycle stability due to better interaction of $\mathrm{V}_{2} \mathrm{O}_{5}$ particles with graphene surfaces and homogeneous dispersion of the precursor materials.

Supplementary Materials: Supplementary materials can be found at http://www.mdpi.com/2311-5629/ 2/3/21/s1.

Author Contributions: Xuewei Fu and Sadhan C. Jana conceived and designed the experiments; Xuewei Fu and Yuming Chen performed the experiments; Xuewei Fu and Yuming Chen analyzed the data; Xuewei Fu wrote the first draft; Sadhan C. Jana and Yu Zhu modified the draft. All authors reviewed the final draft.

Conflicts of Interest: The authors declare no conflict of interest.

\section{References}

1. Kötz, R.; Carlen, M. Principles and Applications of Electrochemical Capacitors. Electrochim. Acta 2000, 45, 2483-2498. [CrossRef]

2. Zhi, M.; Xiang, C.; Li, J.; Li, M.; Wu, N. Nanostructured Carbon-Metal Oxide Composite Electrodes for Supercapacitors: A Review. Nanoscale 2013, 5, 72-88. [CrossRef] [PubMed]

3. Fu, M.; Ge, C.; Hou, Z.; Cao, J.; He, B.; Zeng, F.; Kuang, Y. Graphene/vanadium Oxide Nanotubes Composite as Electrode Material for Electrochemical Capacitors. Physica B 2013, 421, 77-82. [CrossRef]

4. Jiang, H.; Ma, J.; Li, C. Mesoporous Carbon Incorporated Metal Oxide Nanomaterials as Supercapacitor Electrodes. Adv. Mater. 2012, 24, 4197-4202. [CrossRef] [PubMed]

5. Lokhande, C.D.; Dubal, D.P.; Joo, O.S. Metal Oxide Thin Film Based Supercapacitors. Curr. Appl. Phys. 2011, 11, 255-270. [CrossRef]

6. Zeng, F.; Feng, G.; Nguyen, S.T.; Duong, H.M. Advanced Multifunctional Graphene Aerogel-Poly (methyl methacrylate) Composites: Experiments and Modeling. Carbon 2015, 81, 396-404.

7. Zhang, X.; Sui, Z.; Xu, B.; Yue, S.; Luo, Y.; Zhan, W.; Liu, B. Mechanically Strong and Highly Conductive Graphene Aerogel and Its Use as Electrodes for Electrochemical Power Sources. J. Mater. Chem. 2011, 21, 6494-6497. [CrossRef]

8. Choi, D.; Blomgren, G.E.; Kumta, P.N. Fast and Reversible Surface Redox Reaction in Nanocrystalline Vanadium Nitride Supercapacitors. Adv. Mater. 2006, 18, 1178-1182. [CrossRef]

9. Niu, Z.; Liu, L.; Zhang, L.; Shao, Q.; Zhou, W.; Chen, X.; Xie, S. A Universal Strategy to Prepare Functional Porous Graphene Hybrid Architectures. Adv. Mater. 2014, 26, 3681-3687. [CrossRef] [PubMed]

10. Wang, X.; Jana, S.C. Synergistic Hybrid Organic-Inorganic Aerogels. ACS Appl. Mater. Interfaces 2013, 5, 6423-6429. [CrossRef] [PubMed]

11. Sathiya, M.; Prakash, A.S.; Ramesha, K.; Tarascon, J.M.; Shukla, A.K. $\mathrm{V}_{2} \mathrm{O}_{5}$-Anchored Carbon Nanotubes for Enhanced Electrochemical Energy Storage. J. Am. Chem. Soc. 2011, 133, 16291-16299. [CrossRef] [PubMed]

12. Livage, J. Sol-gel Chemistry and Electrochemical Properties of Vanadium Oxide Gels. Solid State Ionics 1996, 86, 935-942. [CrossRef]

13. Wang, Z.; Xu, D.; Huang, Y.; Wu, Z.; Wang, L.; Zhang, X. Facile, Mild and Fast Thermal-decomposition Reduction of Graphene Oxide in Air and Its Application in High-Performance Lithium Batteries. Chem. Commun. 2012, 48, 976. [CrossRef] [PubMed]

14. Augustyn, V.; Dunn, B. Low-potential Lithium-ion Reactivity of Vanadium Oxide Aerogels. Electrochim. Acta. 2013, 88, 530-535. [CrossRef]

15. Chaput, F.; Dunn, B.; Fuqua, P.; Salloux, K. Synthesis and Characterization of Vanadium Oxide Aerogels. J. Non Crystalline Solids 1995, 188, 11-18. [CrossRef]

16. Wang, G.; Yang, J.; Park, J.; Gou, X.; Wang, B.; Liu, H.; Yao, J. Facile Synthesis and Characterization of Graphene Nanosheets. J. Phys. Chem. C 2008, 112, 8192-8195. [CrossRef]

17. Le, D.B.; Passerini, S.; Guo, J.; Ressler, J.; Owens, B.B.; Smyrl, W.H. High Surface Area $\mathrm{V}_{2} \mathrm{O}_{5}$ Aerogel Intercalation Electrodes. J. Electrochem. Soc. 1996, 143, 2099-2104. [CrossRef]

18. Petkov, V.; Trikalitis, P.N.; Bozin, E.S.; Billinge, S.J.L.; Vogt, T.; Kanatzidis, M.G. Structure of $\mathrm{V}_{2} \mathrm{O}_{5} \cdot \mathrm{nH}_{2} \mathrm{O}$ Xerogel Solved by the Atomic Pair Distribution Function Technique. J. Am. Chem. Soc. 2002, 124, 10157-10162. [CrossRef] [PubMed] 
19. Yu, J.; Liu, S.; Cheng, B.; Xiong, J.; Yu, Y.; Wang, J. Polymer-directed Large-scale Synthesis of Single-Crystal Vanadium Oxide Nanobelts. Mater. Chem. Phys. 2006, 95, 206-210. [CrossRef]

20. Baddour, R.; Pereira-Ramos, J.P.; Messina, R.; Perichon, J. A Thermodynamic, Structural and Kinetic Study of the Electrochemical Lithium Intercalation into the Xerogel $\mathrm{V}_{2} \mathrm{O}_{5} \cdot 1.6 \mathrm{H}_{2} \mathrm{O}$ in a Propylene. J. Electroanal. Chem. 1991, 314, 81-101. [CrossRef]

21. Aldebert, P.; Baffier, N.; Gharbi, N.; Livage, J. Intercalation de Solvants Organiques Polaires dans la Structure Lamellaire des gels de $\mathrm{V}_{2} \mathrm{O}_{5}$. Mater. Res. Bull. 1981, 16, 669-676. [CrossRef]

22. He, H.; Gao, C. Supraparamagnetic, Conductive, and Processable Multifunctional Graphene Nanosheets Coated with High-Density $\mathrm{Fe}_{3} \mathrm{O}_{4}$ Nanoparticles. ACS Appl. Mater. Interfaces 2010, 2, 3201-3210. [CrossRef] [PubMed]

23. Jeong, H.K.; Jin, M.H.; An, K.H.; Lee, Y.H. Structural Stability and Variable Dielectric Constant in Poly Sodium 4-Styrensulfonate Intercalated Graphite Oxide. J. Phys. Chem. C 2009, 113, 13060-13064. [CrossRef]

24. Zhou, X.; Wu, G.; Wu, J.; Yang, H.; Wang, J.; Gao, G.; Cai, R.; Yan, Q. Multiwalled Carbon Nanotubes- $\mathrm{V}_{2} \mathrm{O}_{5}$ Integrated Composite with Nanosized Architecture as a Cathode Material for High Performance Lithium Ion Batteries. J. Mater. Chem. A 2013, 1, 15459-15468. [CrossRef]

25. Park, S.H.; Bak, S.M.; Kim, K.H.; Jegal, J.P.; Lee, S.I.; Lee, J.; Kim, K.B. Solid-state Microwave Irradiation Synthesis of High Quality Graphene Nanosheets under Hydrogen Containing Atmosphere. J Mater. Chem 2011, 21, 680-686. [CrossRef]

26. Wu, Z.S.; Ren, W.; Gao, L.; Zhao, J.; Chen, Z.; Liu, B.; Tang, D.; Yu, B.; Jiang, C.; Cheng, H.M. Synthesis of Graphene Sheets with High Electrical Conductivity and Good Thermal Stability by Hydrogen Arc Discharge Exfoliation. ACS Nano. 2009, 3, 411-417. [CrossRef] [PubMed]

27. Tuinstra, F.; Koenig, J.L. Raman Spectrum of Graphite. J Chem. Phys. 1970, 53, 1126-1130. [CrossRef]

28. Ferrari, A.C.; Robertson, J. Raman Spectroscopy of Amorphous, Nanostructured, Diamond-Like Carbon, and Nanodiamond. R. Soc. A: Math. Phys. Eng. Sci. 2004, 362, 2477-2512. [CrossRef] [PubMed]

29. Yang, S.B.; Feng, X.L.; Ivanovici, S.; Müllen, K. Fabrication of Graphene-Encapsulated Oxide Nanoparticles: Towards High-Performance Anode Materials for Lithium Storage. Angew. Chem. Int. Ed. 2010, 49, 8408-8411. [CrossRef] [PubMed]

30. Reddy, R.N.; Reddy, R.G. Porous Structured Vanadium Oxide Electrode Material for Electrochemical Capacitors. J. Power Sources 2006, 156, 700-704. [CrossRef]

31. Liu, Y.; Clark, M.; Zhang, Q.; Yu, D.; Liu, D.; Liu, J.; Cao, G. V $2 \mathrm{O}_{5}$ Nano-Electrodes with High Power and Energy Densities for Thin Film Li-Ion Batteries. Adv. Energy Mater. 2011, 1, 194-202. [CrossRef]

32. Du, G.; Seng, K.H.; Guo, Z.; Liu, J.; Li, W.; Jia, D.; Cook, C.; Liu, Z.; Liu, H. Graphene- $\mathrm{V}_{2} \mathrm{O}_{5} \cdot \mathrm{nH}_{2} \mathrm{O}$ Xerogel Composite Cathodes for Lithium Ion Batteries. RSC Adv. 2011, 1, 690-697. [CrossRef]

33. Wang, H.W.; Yi, H.; Chen, X.; Wang, X.F. One-step Strategy to Three-Dimensional Graphene/VO 2 Nanobelt Composite Hydrogels for High Performance Supercapacitors. J. Mater. Chem. A 2014, 2, 1165-1173. [CrossRef]

34. Wang, J.L.; Shi, Z.X.; Fan, J.C.; Ge, Y.; Yin, J.; Hu, G.X. Self-assembly of Graphene into Three-Dimensional Structures Promoted by Natural Phenolic Acids J. Mater. Chem. 2012, 22, 22459-22466. [CrossRef]

35. Wei, T.Y.; Chen, C.H.; Chien, H.C.; Lu, S.Y.; Hu, C.C. A Cost-Effective Supercapacitor Material of Ultrahigh Specific Capacitances: Spinel Nickel Cobaltite Aerogels from an Epoxide-Driven Sol-Gel Process. Adv. Mater. 2010, 22, 347-351. [CrossRef] [PubMed]

36. Zhang, J.T.; Jiang, J.W.; Li, H.L.; hao, X.S. A High-Performance Asymmetric Supercapacitor Fabricated with Graphene-Based Electrodes. Energy Environ. Sci. 2011, 4, 4009-4015. [CrossRef]

37. Boukhalfa, S.; Evanoff, K.; Yushin, G. Atomic Layer Deposition of Vanadium Oxide on Carbon Nanotubes for High-Power Supercapacitor Electrodes. Energy Environ. Sci. 2012, 5, 6872-6879. [CrossRef]

38. Toupin, M.; Brousse, T.; Belanger, D. Influence of Microstucture on the Charge Storage Properties of Chemically Synthesized Manganese Dioxide. Chem. Mater. 2002, 14, 3946-3952. [CrossRef]

(C) 2016 by the authors; licensee MDPI, Basel, Switzerland. This article is an open access article distributed under the terms and conditions of the Creative Commons Attribution (CC-BY) license (http://creativecommons.org/licenses/by/4.0/). 